\title{
Erratum to: Method and Equipment for Infrared and Ultrasonic Thermographic Testing of Large-Sized Complex-Shaped Composite Products
}

\author{
A. O. Chulkov ${ }^{a, *}$, D. A. Nesteruk ${ }^{a}$, B. I. Shagdyrov ${ }^{a}$, and V. P. Vavilov ${ }^{a}$ \\ ${ }^{a}$ Tomsk Polytechnic University, Tomsk, 634050 Russia \\ *e-mail: chulkovao@tpu.ru \\ Received November 1, 2021; revised November 1, 2021; accepted November 1, 2021
}

DOI: $10.1134 / \mathrm{S} 1061830921090114$

The article "Method and Equipment for Infrared and Ultrasonic Thermographic Testing of LargeSized Complex-Shaped Composite Products”, written by A.O. Chulkov, D.A. Nesteruk, B.I. Shagdyrov, and V.P. Vavilov, was originally published electronically in Springer-Link on October 4, 2021 without Open Access. After publication in volume 57, issue 7, pages 619-626 the authors decided to make the article an Open Access publication. Therefore, the copyright of the article has been changed to (C) The Author(s) 2021 and the article is forthwith distributed under the terms of a Creative Commons Attribution 4.0 International License (http://creativecommons.org/licenses/by/4.0/, CC BY), which permits use, duplication, adaptation, distribution and reproduction of a work in any medium or format, as long as you cite the original author(s) and publication source, provide a link to the Creative Commons license, and indicate if changes were made.

The original article can be found online at https://doi.org/10.1134/S1061830921070044 